\title{
Redesigning the Future of Experiential Learning
}

\author{
Neil B. Niman \\ University of New Hampshire \\ Jennifer R. Chagnon \\ University of New Hampshire
}

In response to the call for more work-ready graduates, many academic programs have looked toward experiential learning to close the gap between theory and practice. Rather than sending students off campus, we have chosen instead to create an on-campus experience consisting of a series of two credit courses. Each course is the outcome of a collaborative process that relies on the expertise and experience of industry professionals who help develop and ultimately deliver a customized learning experience. These activity-based, guided learning experiences provide an inside look at how core knowledge can be applied to real work processes and problems.

Keywords: experiential learning, course design, practice-based learning, skills, tacit knowledge

\section{INTRODUCTION}

Experiential learning is often thought of as an activity that takes place off campus in the form of an internship, study abroad experience, consulting project, or service-learning experience (Kuh, 2008). It is an attempt to provide students with an opportunity to put their knowledge into practice, get a sense of how life works outside of academia, and potentially make an important professional connection (Ewing and Ewing, 2017). Within the context of business education, the connections between industry and the core curriculum are even more important. Core theoretical concepts derive much of their value when they can be applied to real problems in real time to meet the challenges faced by today's business enterprises (McKeen et al., 2019).

Much of the work on experiential learning is based on the four-step learning model advanced by David Kolb (1984) and expanded in Kolb and Kolb (2005). Kolb's theory of self-directed experiential learning begins with a concrete experience. The experience leads to a period of reflection to gain perspective. This promotes abstract thinking about the experience in order to develop a sense of meaning. All of this leads to action through additional experimentation based on what has been learned. However, the effectiveness of Kolb's approach to experiential learning is mixed (Schenck \& Cruickshank, 2015; Burchet et al., 2019).

In contrast to Kolb's self-directed learning experiences, we have created an entire program comprised of guided experiences which are led by industry professionals and carefully crafted around a particular set of learning and developmental goals (Meyer, 2004; Kirschner et al., 2006; Nargundkar, 2014). Processbased, these guided experiences seek to leverage the wisdom of an industry professional, or practitioner, that has been developed over years of work. When combined with carefully designed activities, a 
comprehensive learning experience can be constructed. It is experiential learning by design. A design that aims to accelerate the learning process by giving the student an opportunity to gain insights as they learn by doing with the assistance of an industry practitioner. A practitioner who can draw from their personal experience and therefore assist in making important connections between theory and practice.

Each experiential learning experience is carefully crafted before any student ever enters a classroom. We apply a design process that begins with a course narrative that is rooted in the expertise of the selected practitioner who will be guiding the learning experience. What we want the student to learn is the result of a deliberative process that matches learning and developmental goals to the course narrative. This narrative serves as a scaffold for organizing key concepts that are paired with activities designed to provide students with the type of hands-on experience they might receive in a real work environment.

Milestones are embedded in the learning process and designed to give students an opportunity to share what they have learned and to receive useful feedback on their progress. This provides the student with an opportunity to reflect on what they have accomplished and what still needs to be done. By recognizing tasks have gone amiss and accelerating actions that are working well, students can leave the experience with a sense of accomplishment and a greater understanding of approaches and actions required for success in a professional setting.

We begin with a review of the most popular methods that seek to integrate experiential learning. We then introduce a unique approach that we have created at the Peter T. Paul College of Business and Economics (Paul College) at the University of New Hampshire called Business in Practice. After a brief overview of the program, we look more closely at what we call Practice-Based Learning. We conclude with some thoughts about where experiential learning is heading and how it can enhance the core curriculum of any academic program.

\section{BRIDGING THE GAP BETWEEN THEORY AND PRACTICE}

An academic discipline is structured around a core body of knowledge that is required to earn a degree. This core knowledge consists of those fundamental concepts that serve as the foundation for the functional areas that comprise a major offered as part of an accredited program. However, developing a deep understanding of a set of theoretical principles is not the same as grasping how to deploy that knowledge in the field or within a particular context.

To bridge the gap between theory and practice, many professors use case studies to infuse a dose of reality into their teaching (Bridgman and Cummings, 2016; Nohria \& Rivkin, 2018). The challenge with using cases is that they often look at the past rather than toward the future and are subject to the limitations and biases of both the case writer and the professor who selects it (Mitnick, 2009). Others adopt simulations which place the student in an active role that enables them to adapt to various scenarios that mimic the functioning of a real company (Chernikova et al., 2020; Lovelace et al., 2016; Mohsen, 2019). While this gets students closer to a real decision-making role, simulations are only as effective as the vision of its creators, the technology used to build them and the resources available to keep them current and up to date.

Instead of a team of students working collaboratively to achieve success in a simulated environment, similar benefits could accrue to a group working on a real company project (Smith \& Gibson, 2016; Tofighi, 2021). Projects offer many of the benefits associated with a simulation. The advantage is that they are often more nuanced because they are designed around an actual rather than an imagined business project. Moreover, rather than conforming to a fixed set of parameters contained in the simulation's algorithm, it can instead capture the richness that is often associated with the needs of a specific company rather than a generic set of rules (Kayes, 2002; Ungaretti, et al., 2015). Projects, however, often do not come with the associated back story that would enable someone to understand the strategy along with the interpersonal and organizational dynamics that provide the underlying rationale for why things are the way they are or what change (if any) is even possible.

Because of the limited access to industry professionals that is found with cases, simulations, and projects, internships led by a real corporate mentor doing real projects with a real company, are often held as the gold standard when it comes to experiential learning (Binder et al., 2015). In the right set of 
circumstances, the student has an opportunity to not only gain an inside look into how business is done, but they are also able to gain some valuable soft skills that will prepare them for later success. However, given the variability found in terms of projects, mentorship, guidance and work environments, the internship may be nothing more than a wasted opportunity as the responsibilities assigned and the tasks performed look more like busy rather than substantive work.

\section{BUSINESS IN PRACTICE}

Conventional approaches to experiential learning have their place in any degree program. However, when thinking about the future of experiential learning, we elected to take a distinctive approach and in turn, created Business in Practice (BiP). BiP is an educational system designed to tap the wisdom of industry professionals in a structured environment that embodies the best of experiential learning. Each experience has the student learn by doing under the guidance of a working professional who brings their culture, values, and competences into the classroom. Students work with those current tools and techniques that are actually used while getting feedback from professionals in the field.

$\mathrm{BiP}$ courses employ active learning and projects to construct an environment where students can take risks, learn from failure, ask candid questions, and build a rich portfolio of experiences and skills (McCale, 2008). They enable Paul College students to see firsthand how business-oriented principles can be applied to achieve real world outcomes in courses designed to give them a head start with those tools, techniques and skills that are desired most by today's employers. It is experiential learning by design; a design that accelerates the learning process by giving the student an opportunity to gain insights as they learn by doing under the guidance of a professional with a record of accomplishment in the field.

Within the BiP program, students are required to take 4 two credit courses as part of their degree program. These courses are designed to "sit on top" of the existing curriculum and serve as a bridge between business practice and the foundational knowledge taught in the core curriculum. They are designed to focus on those tools, skills, applications, and experiences that are actively sought after by the business community (Coffey et al., 2020).

Rather than thinking narrowly in terms of skill development, we instead sought a broader conception that would promote the development of a well-rounded business school graduate. BiP courses are organized into four intelligences: Social, Analytical, Competitive, and Professional. Each student must take a course from each of the intelligences to successful complete the degree in business administration.

In today's global economy where responsibilities often span continents and jobs are constantly changing almost as fast as new technologies are introduced on what seems like a daily basis, the need to navigate complex social relationships and a wide array of environments (Social Intelligence) is crucial for success. The ability to communicate effectively, to collaborate or to lead teams, to be flexible in thought and action, and to employ EQ to achieve success embody what we mean by social intelligence. For example, in the course Business Networking \& Social Selling, students learn to leverage social media platforms and networks to improve their sales strategies and customer relationships. An emphasis is also placed on understanding the complexities of social networks and honing communication skills.

As information technology becomes a part of every facet of our lives, the amount of data that can be (and is being) collected is astonishing. Decision making at all levels within an organization is now being driven by this wealth of information. Those solutions and strategies most likely to form the foundation for success requires a graduate capable of using data to analyze and evaluate ideas, make evidence-based decisions (Analytical Intelligence) and then communicate and apply them in effective ways. We want to develop graduates who are active problem solvers capable of robust thinking, can rapidly prototype ideas, and can distill and disseminate a vast array of data for a variety of stakeholders. In Python for Business Analytics, students are initially guided through the base language elements, version control systems, and repeatable reporting techniques in order to experience Python's ease of use, data capabilities, and an introduction to its large open-source community. The emphasis then shifts to the application of Python to real-world business scenarios in order to maximize the impact and effectiveness of data-driven analysis. 
Markets have grown more complex as the composition of customers and competitors has changed with the emergence of a truly global marketplace. Understanding these changes and forming the appropriate response (Competitive Intelligence) is required for achieving success in today's economy. Students need to understand the diversity of people and interests that will influence the mechanisms and culture within a company, what products are produced and for whom, and how the complexities of the global economy will play an important role in determining success or failure. As an example, Paul College students analyze and execute on a digital content and search engine optimization strategy for a New Hampshire small business in the BiP course Content Strategy \& SEO. Students are tasked with mining information about the small business's competitors/market as well as creating buyer personas and a buyer's journey in order build and execute the strategy. At the culmination of the experience, students evaluate the campaign and present the results to the client.

Students need experience in applying their discipline-based knowledge in actual business situations and environments. The BiP Program is designed to help a student to understand how to leverage their specific skills and talents within a professional domain and expand their professional networks (Professional Intelligence). In Building an Inspired Personal Brand, Paul College students become their own clients. Brand management techniques are applied to the growing field of personal branding. Students must completely overhaul their professional presence into a coherent, consistent, targeted brand based on their individual skillsets, strengths and weaknesses, values, and purpose. Students build a brand playbook that they deploy across their social media channels and networks, as well as through a two-minute elevator pitch.

The Business in Practice program offers around 65 BiP courses per academic year with a typical class size of twenty-five students. This makes it possible to leverage the efforts of a single professional who can guide a much larger number of students at a single point in time. Students can also use other experiential learning opportunities to earn credit toward fulfilling their BiP requirement. By operating at such scale for a population of approximately 2,400 students, the program affords each student multiple opportunities to work with an industry professional in an area of interest.

\section{THE BiP EXPERIENCE}

Business in Practice courses are much more process than outcome oriented. Each course takes the student on a journey that has them completing a project or series of steps that are designed to enhance their understanding of how things are done in actual business settings. We ask BiP practitioners to share their work experience to create a learning journey that answers the why something is done a certain way as much as what and where. BiP courses steer students through an experience where they must engage and respond to circumstances that are similar to what they might encounter after graduation. All of this under the watchful eye of a practitioner who can share insights and reflection points along the way.

By utilizing a design process that is tailored to the goals of the BiP program, it becomes possible to create a consistent experience across the entire program. While all courses share a common vision and design process, they are not exactly the same. We encourage each practitioner to infuse their course with a sense of what it might be like to work at a particular company or in a distinct role. We want Paul College students to get a taste of the diverse work environments that populate the employment landscape, however, within an active learning context and with a set of well-defined learning and developmental goals. Because all BiP courses share the same design process and philosophy, students quickly acclimate to the learning environment as they actively engage with the material and each other.

By offering a consistent experience with a diverse set of offerings, students have an opportunity to explore a number of different industries and roles where they can (hopefully) identify at least one that sparks their passion, interest, and future direction. Through the application of knowledge, they can gain a greater appreciation of a particular skill, tool, or technique. By exposing students to professional rather than academic standards, business cultures, and ways of sharing and processing feedback, they can set expectations when searching for an employer of choice or role that will utilize their strengths. 
The goal is to have Paul College students end up with improved skillsets, a better understanding of what they like, a new appreciation of what will be expected in the workplace, compelling stories that demonstrate their abilities, and a connection to a business professional who can open doors and extend their professional network. Many of the BiP courses lead to a connection to someone they might not otherwise meet and receive advice about how to advance their career. For a select few, their BiP experience has led to an internship or job offer. Above all else, it provides Paul College students with an opportunity to differentiate themselves from the average business school student by providing them with a collection of experiences they can articulate to showcase the competencies they have developed by completing the program.

\section{PRACTICE-BASED LEARNING}

All of the BiP learning experiences incorporate what we call Practice-Based Learning. Practice-Based Learning is a guided form of experiential learning that employs active learning (Bonwell \& Eison, 1991) in a controlled environment to ensure a consistent high-quality experience that accelerates the development of those professional skills desired most by employers (NACE, 2020; Margarit, 2019). The BiP program uses Practice-Based Learning to transform the equivalent of an internship into an on-campus experience. It is based on three essential elements. They are:

- A Guided Shared Experience - Industry professionals are brought into the classroom to share their experience and guide their students through a journey that is similar to their work environment and processes.

- ISA $^{2}$ Learning - learning that is informal, situated, active and applied.

- Professional Progress - an emphasis is placed on the intentional development of professional skills.

Insider knowledge may take years to acquire through a process of trial and error, mentorship, or access to a specific network or set of experiences. This insider, or tacit knowledge is rarely written down. That led us to wonder if we could create a learning experience that would allow others to tap into the insider knowledge of an industry professional in order to accelerate a student's own professional development. By creating a guided experience, the goal is to reduce the amount of trial and error and increase the reflection that is often required to develop the insider knowledge that is crucial for successfully navigating real work situations. It is about using the experience of others to accelerate the learning process (Sternberg et.al., 1995; Sternberg et.al., 1999). Less repetition to achieve more learning.

The program strives for authenticity in each of the BiP learning experience designs. Industry professionals are asked to speak from their own experience and to expose their students to the professional norms, terminology, tools, standards, and expectations that reflect their work history. They share the expertise they have gained from years of work experience within a learning narrative designed to put their knowledge into practice.

$\mathrm{BiP}$ courses are all credit/fail, but that does not preclude industry professionals from sharing how their student's work would be evaluated within a professional environment. By making each learning experience reflective of a particular corporate culture and way of doing things, Paul College students get exposed to the wide array of possibilities that exist in the working world. In Content Strategy and SEO, students work collaboratively in teams using current communication tools such as Slack or Microsoft Teams, and the course often meets virtually in their teams or with clients through Zoom, prescribing to the company's dayto-day work habits and environment. The student work is evaluated as a team and as a class. The instructor and peers offer feedback and evaluation of the work in progress, highlighting exemplary work while returning work or requesting more development from teams that are underperforming. The final evaluation is impacted by the client feedback and if the teams met the scope of work and quality standards.

All of the BiP experiences utilize what we call ISA $^{2}$ (informal, situated, active and applied) learning. It is designed to be informal so that our students can take advantage of the tacit knowledge and experience that our working practitioners have developed over their professional careers (Coffield, 2000; Marsick \& 
Volpe, 1999). Learning is situated within the culture, standards, and way of doing things that BiP practitioners bring with them into the classroom (Lave \& Wenger, 1991; Brown, et al., 1989). It is both active and applied (Cummings, 2018). Students learn by doing as they actively engage with the material, each other, and the BiP practitioner.

In the BiP course on product licensing taught by the Vice President for Licensing and Strategic Initiatives at Vera Bradley, students are challenged with the practitioner's actual responsibility: to develop a potential licensing opportunity for the brand within the travel, wellness, or home category. Similar to the company's structure, the students assume roles on licensing teams and are tasked to identify a potential prospect, to vet the opportunity's potential value, and to develop a strategic plan for licensing. The practitioner acts as a guide and provides the necessary context, structure and company resources needed to provide a rich learning environment, as well as guidance on navigating the process and external resources.

The practitioner sets target deadlines for phases of the project that are used as reflection points for teams to share and improve their intended actions. To broaden the experience, guest experts/professionals are brought in to share their specific knowledge and lens to provide additional context, guidance, or feedback. Student teams decide on the actions to complete the process and develop a competitive proposal that may be acted upon by the company. At the end of the term, their strategic licensing plan is evaluated using Vera Bradley standards.

While our experiences have a well-defined set of learning goals, we are also focused on the professional development progress of Paul College students. Therefore, a set of developmental goals is embedded in the design of BiP learning experiences. These goals set expectations for how students develop their professional skills and abilities as they expand their knowledge in a specific area. The BiP design process includes content/activities/milestones that assist in the development of those soft skills most desired by employers. Rather than seeing soft skill development as the by-product of the learning process, it is viewed as being fundamental to the success of a carefully crafted learning experience (Pasquerella, 2019). For example, we encourage our practitioners to provide low stakes opportunities for their students to learn how to overcome failure to build a pathway toward resiliency.

In the Business of Podcasting course, the entire class works collectively to develop a concept for a podcast. Smaller teams are created and given the responsibility of producing an individual episode that fits within the broader theme. The podcast is posted online, and students are tasked with developing a marketing plan to attract listeners and a revenue model to support the podcast. While producing the tangible deliverables, students are also utilizing skills in collaboration, communication, and consensus-building to accomplish the tasks. In some instances, the podcast episode may not meet the standards set by the class or may be panned by the audience. The team will need to quickly incorporate feedback and rerecord portions of an episode. All of this is guided by a professional who has over fifteen years of experience and is one of the original creators of the Mac Observer series of podcasts.

As mentioned above, many of the BiP experiences have students working toward a final deliverable where they might be pitching a particular investment opportunity, selling a specific concept, or propose bringing a new product to market. Often, students are making a presentation to a group of executives who will make the final determination of what constitutes a successful outcome and which ideas are not worthy of further development. Knowing your audience, understanding what is feasible, and meeting cultural norms are all elements that will determine the success of a final proposal or presentation for that particular audience and cultivate a student's professional development.

\section{COURSE DEVELOPMENT}

BiP courses are significant learning experiences (Fink, 2013). Each is carefully crafted to leverage the expertise and past work history of our industry professionals within a context where the students are active rather than passive participants in the process. The courses are less about disseminating a body of knowledge and are more focused on the development of the student as a creative problem solver, collaborator, communicator, or other qualities designed into the fabric of the course. 
A challenging part of the course development process is in helping the industry professional organize his/her thought process in a manner that lends itself to the construction of a coherent narrative. It is one thing to be an expert in what you do and something entirely different when it comes to helping others understand what needs to be done in a given set of circumstances. In response, we have developed a process to collaboratively design over $60+\mathrm{BiP}$ learning experiences.

Developing a coherent narrative is only the first step in the construction of a BiP learning experience. We encourage BiP practitioners to keep the amount of lecturing to a minimum and spend a great deal of time in thinking of how to activate the course so that the students are engaged with the material and each other in a manner that accelerates the learning process. Whether it is working on real projects or active engagement with each other and guest speakers, each course concept is paired with an active component that provides a key takeaway that contributes to a portfolio of skills and experiences.

To ensure consistency and a high-quality academic experience, we have developed an extensive guide and set of interactive tools that walk both program administrators and potential practitioners through the course development process. The goal in creating career-ready graduates is to go beyond the current trend of skillifying a résumé (EMSI, 2021). Instead, we concentrate on the construction of a narrative that can be used to articulate an experience that demonstrates a skill desired by a potential employer. We, therefore, incorporate a commonly used method for handling behavioral interview questions known as the STAR approach (Boogaard, 2021) into our design process. It is predicated on what a student might say to a potential employer when asked about their BiP experience.

An expanded version of the STAR approach incorporates an additional $\mathrm{R}$ to acknowledge a reflection component that focuses on what was learned from the experience. This expanded approach STAR $^{2}$, incorporates the following elements:

- Situation - the context that is current, relevant and reflects the industry professional's work experience as well as the roles assigned to students working individually or in teams.

- Task - the goal, project, or challenge.

- Action -the steps required to complete the tasks.

- Result - the outcome(s) and impact of the action.

- Reflection - an opportunity for the student to consider what they learned along with areas of importance or improvement.

The STAR ${ }^{2}$ method is used at the start of our course development process and is an integral part of the proposal phase. During this initial phase, we learn about the professional qualifications of a potential BiP practitioner, what they are most passionate about, and discuss how we might draw from their experience and turn it into a BiP learning experience. Through an ideation session (or series of sessions), a concept is developed that addresses a need in the marketplace and can serve as an extension of our core curriculum.

To understand how we employ the STAR ${ }^{2}$ method, we can use the example of our most popular course to date which is called How to Talk Stocks. Early in the development process, we learned that the Finance Department was not interested in another course that teaches students how to select stocks. What they were really interested in was a course that taught students how to persuasively communicate their investment recommendations to a variety of audiences and media. Through a mutual connection, we were able to recruit an alumnus who publishes his own investing newsletter and has written stories and hosted a podcast for the Motley Fool. 


\section{FIGURE 1 \\ THE STAR ${ }^{2}$ APPROACH TO COURSE DESIGN}

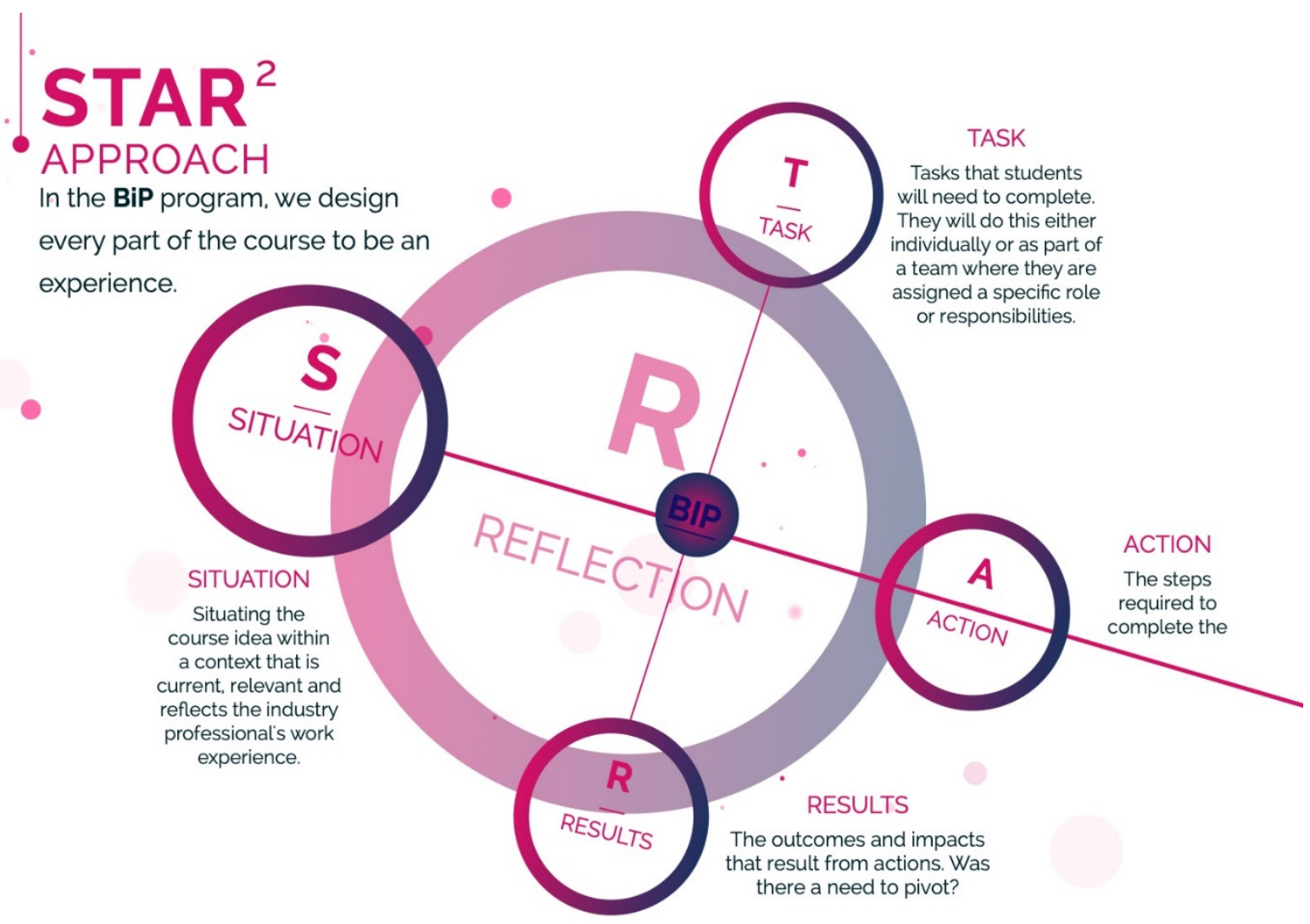

The course uses the backdrop of investing to teach students how to frame data, communicate ideas, and persuade potential investors about a stock pick. Students select a financial asset and undergo a series of scenarios and roles (Situation) requiring them to "talk" about their investment selection across a variety of media (Task). Students must analyze the potential scenario to construct a compelling pitch or article to persuade the audience (Action). Work in progress is shared (Result). Peer and practitioner feedback leads to real-time improvements and an opportunity to consider what has been accomplished and what might be done differently the next time around (Reflection).

\section{THE FUTURE OF EXPERIENTIAL LEARNING}

Creating learning experiences guided by industry professionals is just the next step toward redesigning experiential learning. At best, they are a close approximation of what a student might encounter in a particular workplace with a specific set of responsibilities. It is still a classroom-based experience. To take experiential learning to an even higher level, we have been developing real working experiences. Our first effort has been to create a student-run digital marketing agency.

Digital marketing is one area where the technology is changing so quickly that it is even challenging for those who are working in the industry to keep up. After talking to a number of agencies (the type that would most likely hire our graduates), we learned how important it would be for our students to not only understand how to use the most current set of tools, but to have an experience where they were able to put them into practice. In many ways, the ability to demonstrate how a student has put their knowledge into practice through some meaningful experience is more important than a certification or module as part of a course in the core curriculum. It is one thing to pass a test showing that you can manipulate a tool, it is quite 
something else to show that you have successfully applied that tool in a significant way for a client or to solve a real business problem (McArthur et al., 2017).

In order to provide Paul College students with the types of experiences that employers are seeking, we created Voice Z Digital which is a student-run digital marketing agency. Voice $\mathrm{Z}$ is a powerful example of what is possible when Practice-Based Learning is taken to the next level. For the most part, the students in Voice $\mathrm{Z}$ work with small businesses who either do not have the resources to hire an established agency or understand where they would benefit the most from outside help. In this way, Voice Z serves as an incubator that works with established businesses with a limited digital presence and helps grow their needs and interests to the point where they can be handed off to a professional agency.

Clients are sourced through a partnership with the NH Small Business Development Center (SBDC). The SBDC has a team of advisors spread throughout the state of New Hampshire who are in constant contact with small businesses in need of additional help and support. Through an application process, selected SBDC clients gain access to a talented group of students that provide a digital audit and recommendations for further action. The client can then contract with the agency to provide some services, get a referral to a local agency, or receive some advice about how they might do it themselves.

For all intents and purposes, Voice $\mathrm{Z}$ is a real digital agency. They work with existing businesses that have current marketing needs. They must manage the relationships with clients, agency workflow, and the student teams that perform the work. They recruit and train the members of Voice $\mathrm{Z}$ and are responsible for covering costs and generating revenue. It is not an approximation of the real thing; it is the real deal. As a result, graduating seniors can compete successfully with professionals who have been out a few years because they have had a similar experience and a portfolio of work that stacks up against the work performed by other agencies.

\section{CONCLUDING THOUGHTS}

A recent survey commissioned by McGraw Hill found that only $21 \%$ of college students feel very well prepared for a professional career (Hanover, 2016). However, in an alternate Strada/Gallup survey where more than 86,000 education consumers were asked the main reason why they decided to pursue their highest level of education, fifty-eight percent answered that getting a good job was their primary motivation (Strada/Gallup, 2018). If universities are going to remain relevant, how will they close the gap between what consumers of higher education are willing to pay for and what they are actually delivering?

In response, universities have been upgrading their career services offerings, outsourced a portion of the educational process to the corporate sector in the form of internships, or developed other external high impact experiences like study abroad. In addition, many are starting to take a new band-aid approach asking its faculty to skillify their syllabi in an effort to show increased relevance for an educational model that is truly showing its age. None of these efforts are designed to disrupt the traditional university curriculum, the current system of incentives and rewards, or how an institution competes to enhance its reputation.

Meanwhile, technology continues to advance and the calls for the same disruption that has led to radical changes in other industries grows louder and louder (Chamorro-Premuzic \& Frankiewicz, 2019; Mintz, 2020). These crystal ball gazers are first to talk about the consolidation of higher education into the hands of a shrinking number of institutions as the delivery of educational experiences is vested in the hands of genuine educational superstars, the growth of micro credentials begins to displace traditional four year degrees, and the traditional barriers restricting the transfer of credits fall by the wayside.

It is time to rethink how we teach our students, who teaches them and what is taught (Niman, 2014). Traditionally, the division of labor within teaching faculties has been between the tenure track, lecturer track, and part-time adjuncts. Each group teaches the same courses in a similar manner. The only differences are found in the credentials, experience, and demands placed on their time outside of the classroom.

This division of labor within the traditional university does nothing to address the central problem students (and their families) are primarily interested in higher education if it will lead to higher lifetime earnings by providing a superior pathway to professional success. Whether the person at the front of the 
classroom has a Ph.D., has published in a quality journal, or attended a prestigious institution has little bearing on the career outcomes sought by the vast majority of students (Dale \& Krueger, 2002).

The answer is not to continue to view experiential learning as an add-on to a conventional major in an effort to capture a "real world experience." Rather, it is to integrate experiential learning within the curriculum to help build a bridge between theory and practice. By reaching out to practitioners with a story to tell and years of experience to share, it becomes possible to help students become more career-ready in a meaningful way that extends their skill set and helps them discover a little bit about themselves and the best next step to take.

The goal is to accelerate the professional development of a student and place them in a superior position to launch their career. In doing so, we are able to enhance rather than disrupt the core curriculum and bridge the gap between what credentialed faculty have been trained to provide and the needs of employers trying to compete in today's economy. It is redesigning experiential learning as a guided structured process that focuses on career development by tapping into the experience and tacit knowledge of working professionals.

\section{REFERENCES}

Binder, J.F., Baguley, T., Crook, C., \& Miller, F. (2015). The Academic Value of Internships: Benefits Across Disciplines and Student Backgrounds. Contemporary Educational Psychology, 41, 73-82.

Bonwell, C.C., \& Eison, J.A. (1991). Active Learning: Creating Excitement in the Classroom. 1991 ASHE-ERIC HIGHER EDUCATION REPORTS, Washington D.C. Retrieved from https://eric.ed.gov/?id=ED336049

Boogard, K. (2021). The STAR Method: The Secret to Acing Your Next Job Interview. Retrieved from https://www.themuse.com/advice/star-interview-method

Bridgman, T., Cummings, S., \& McLaughlin, C. (2016). Restating the Case: How Revisiting the Development of the Case Method Can Help Us Think Differently About the Future of the Business School. Academy of Management Learning \& Education, 15(4), 726-741.

Brown, J.S., Collins, A., \& Duguid, S. (1989). Situated cognition and the culture of learning. Educational Researcher, 18(1), 32-42.

Burch, G.F., Giambatista, R., Batchelor, J.H., Burch, J.J., Hoover, J.D., \& Heller, N.A. (2019). A MetaAnalysis of the Relationship between Experiential Learning and Learning Outcomes. Decision Sciences Journal of Innovative Education, 17(3), 239-273.

Chamorro-Premuzic, T., \& Frankiewicz, B. (2019). 6 Reasons Why Higher Education Needs to Be Disrupted. Harvard Business Review. Retrieved from https://hbr.org/2019/11/6-reasons-whyhigher-education-needs-to-be-disrupted?registration=success

Chernikova, O., Heitzmann, N., Stadler, M., Holzberger, D., Seidel, T., \& Fischer, F. (2020). SimulationBased Learning in Higher Education: A Meta-Analysis. Review of Educational Research, 90(4), 499-541.

Coffey, C., Burrow, G., Sentz, R., Kirschner, K., \& Saleh, Y. (2020). Resilient Skills: The Survivor Skills That the Class of Covid-19 Should Pursue. EMSI. Retrieved from https://www.economicmodeling.com/resilient-skills/

Coffield, F. (2000). The Necessity of Informal Learning. Bristol, The Policy Press.

Cummings, R. (2018). Building a Case for Active Learning: The Use of Lecture Versus Other Classroom Activities at LMB. Journal of Learning in Higher Education, 14(1), 8-15.

Dale, S.B., \& Krueger, A.B. (2002). Estimating the Payoff to Attending a More Selective College: An Application of Selection on Observables and Unobservables. The Quarterly Journal of Economics, 117(4), 1491-1527.

EMSI. (2021). Skills Required: How higher ed can meet the needs of learners and employers in a skillbased economy. Ebook. Retrieved from https://www.economicmodeling.com/skillabi/

Eraut, M. (2004). Informal Learning in the Workplace. Studies in Continuing Education, 26(2), 247-273. 
Ewing, D.R., \& Ewing, R.L. (2017). Leveraging experiential learning to encourage role transition from "Student" to "Professional": Insights from identity theory. Journal of Marketing Education, 39(3), 132-144.

Fink, L.D. (2013). Creating Significant Learning Experiences: An Integrated Approach to Designing College Courses (Revised and Updated). New Jersey: Jossey Bass.

Hannover Research. (2016). McGraw-Hill Education 2016 Workforce Readiness Survey. Retrieved from https://s3.amazonaws.com/ecommerce-prod.mheducation.com/unitas/corporate/ideas/2016student-workforce-readiness-survey-expanded-results.pdf

Kayes, D.C. (2002). Experiential Learning and Its Critics: Preserving the Role of Experience in Management Learning and Education. Academy of Management Learning and Education, 1(2), 137-149.

Kirschner, P.A., Sweller, J., \& Clark, R.E. (2006). Why Minimal Guidance During Instruction Does Not Work: An Analysis of the Failure of Constructivist, Discovery, Problem-Based, Experiential, and Inquiry-Based Teaching. Educational Psychologist, 41(2), 75-86.

Kolb, A.Y., \& Kolb, D.A. (2005). Learning Styles and Learning Spaces: Enhancing Experiential Learning in Higher Education. Academy of Management Learning \& Education, 4(2), 193-212.

Kolb, D.A. (1984). Experiential Learning: Experience as the Source of Learning and Development. New Jersey: Prentice-Hall.

Kuh, G.D. (2008). High-impact educational practices: What they are, who has access to them, and why they matter. Washington D.C. Association of American Colleges and Universities.

Lave, J., \& Wenger, E. (1991). Situated Learning: Legitimate Peripheral Participation. Cambridge: Cambridge University Press.

Lovelace, K.J., Eggers, F., \& Dyck, L.R. (2016). I do and I understand: Assessing the utility of web-based management simulations to develop critical thinking skills. Academy of Management Learning \& Education, 15, 100-121.

Margarit, V. (2019). Skills Employers Seek in College Graduates. Retrieved from https://www.linkedin.com/pulse/skills-employers-seek-college-graduates-dr-val-margarit/

Marsick, V.J., \& Volpe, M. (1999). The Nature and Need for Informal Learning. Advances in Developing Human Resources, (1), 1-9.

McArthur, E., Kubacki, K., Pang, B., \& Alcaraz, C. (2017). The Employers' View of "Work-Ready" Graduates: A Study of Advertisements for Marketing Jobs in Australia. Journal of Marketing Education, 39(2), 82-93.

McCale, C. (2008). It's Hard Work Learning Soft Skills: Can Client Based Projects Teach the Soft Skills Students Need and Employer's Want? Journal of Effective Teaching, 8(2), 50-60.

McKeen, S., Laufer, K., \& Jester, M. (2019). Assurance of Learning Standards and Scaling Strategies to Enable Expansion of Experiential Learning Courses in Management Education. Texas Education Review, 7(1), 154-174.

Meyer, R.E. (2004). Should There Be a Three-Strikes Rule Against Pure Discovery Learning? The Case for Guided Methods of Instruction. American Psychologist, 59(1), 14-19.

Mintz, S. (2020, September 17). The Disruptions Higher Education Needs. Inside Higher Ed. Retrieved from https://www.insidehighered.com/blogs/higher-ed-gamma/disruptions-higher-educationneeds

Mitnick, B. (2009, April 29). The Case Against the Case Method. Harvard Business Review. Retrieved from https://hbr.org/2009/04/the-case-against-the-case-meth-1

Mohsen, K., Abdollahi, S., \& Omar, S. (2019). Evaluating the Educational Value of Simulation Games: Learner's Perspective. Innovation in Education and Teaching International, 56(4), 517-528.

NACE Staff. (2020). Key Attributes Employers Want to See on Student's Resumes. Retrieved from https://www.naceweb.org/talent-acquisition/candidate-selection/key-attributes-employers-wantto-see-on-students-resumes/ 
Nargundkar, S., Samaddar, S., \& Mulhopadhyay, S. (2014). A Guided Problem-Based Learning (PBL) Approach: Impact on Critical Thinking. Decision Sciences Journal of Innovative Education, 12(2), 91-108.

Niman, N.B. (2014). The Gamification of Higher Education. New York, Palgrave Macmillan.

Nohria, N., \& Rivkin, J.W. (2018, August 30). The Case for Cases. BizEd. Retrieved from https://bized.aacsb.edu/articles/2018/09/the-case-for-cases

Pasquerella, L. (2019, September 19). Yes, Employers Do Value Liberal Arts Degrees. Harvard Business Review. Retrieved from https://hbr.org/2019/09/yes-employers-do-value-liberal-arts-degrees

Schenck, J., \& Cruickshank, J. (2015). Evolving Kolb: Experiential education in the age of neuroscience. Journal of Experiential Education, 38(1), 73-95.

Smith, P.P., \& Gibson, L.A (2016). Project-Based Learning in Colleges of Business: Is it Enough to Develop Educated Graduates? New Directions for Teaching and Learning, 145, 41-47.

Sternberg, R.J., \& Horvath, J.A. (Eds.). (1999). Tacit Knowledge in Professional Practice: Researcher and Practitioner Perspectives. New Jersey. Lawrence Erlbaum Associates.

Sternberg, R.J., Wagner, R.K., Williams, W.M., \& Horvath, J.A. (1995). Testing Common Sense. American Psychologist, 50(11), 912-927.

Strada/Gallup. (2018). Why Higher Ed? Top Reasons U.S. Consumers Choose Their Educational Pathways. Retrieved from https://go.stradaeducation.org/why-higher-ed

Tofighi, M. (2021). Differential Effect of Client-based and Non-client-based Projects on Student's Course Performance and Evaluations. Marketing Education Review. https://doi.org/10.1080/10528008.2021.1871851

Ungaretti, T., Thompson, K.R., \& Miller, A. (2015). Problem-Based Learning: Lessons from Medical Education and Challenges for Management Education. Academy of Management Learning \& Education, 14(2), 173-186. 